graft with the raw freshened margin of the defect. The pericranium, which may be left attached to the graft and projecting beyond it as a surrounding fringe, will facilitate fixation in the new position. The last step in the evolution of the operation was the preservation of a blood supply, by leaving the flap of pericranium and bone attached by a pedicle to the temporal region, so that the vitality of the transplanted tissues was maintained.

\section{TECHNIQUe of Operation}

A flap of scalp is turned back with its base over the temporal region exposing the defect in the skull, and a corresponding area of uninjured bone either behind or in front of the defect (Fig. 1). The incision is planned in such a way that any puckered, broad, or adherent scar remaining from the emergency operation is excised. The greater part of the scar will subsequently be covered with hair, and in frontal injuries the lower incision should follow the line of the eyebrow. The gap in the bone is defined, the pericranium is removed round its margin, and the exposed bone freshened and rawed. A flap of pericranium, equal in size and shape to the area which has

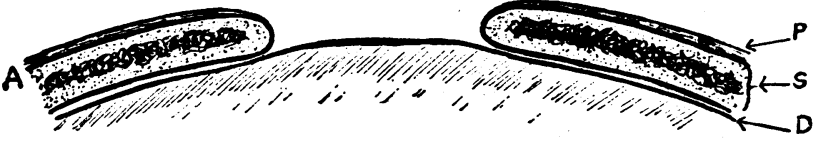

B

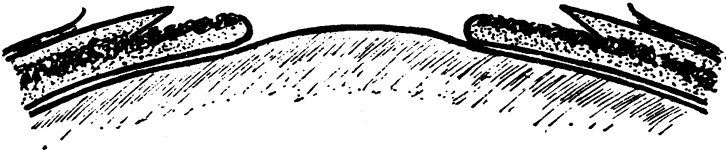

C

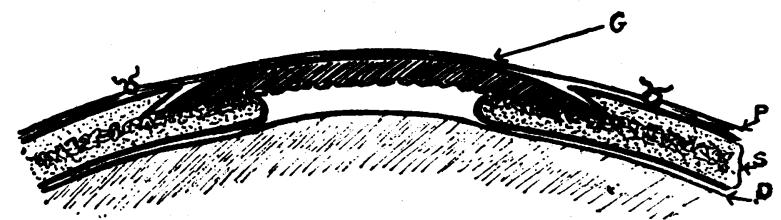

FIG. 4.-Further fixation of the graft is secured by undercutting the margin of the rawed bone (B), and slotting the graft under the overhanging edge $(C) . P$, pericranium; $S$, outer table, diploë, and inner table of skull; $D$, dura mater; $G$, graft.

been cleared, is marked out, and left attached by a pedicle to the temporal region (Fig. 2). The pericranium is raised for a third of an inch round the whole circumference of the flap, but apart from this narrow free edge its attachment to underlying bone is not disturbed. A very sharp, thin-bladed osteotome is used to elevate the outer table, care being taken to keep strictly to the plane of the diploë, so that on the one hand the graft is not unduly thin, and on the other hand the inner table is not encroached upon. A pedunculated flap is now raised consisting of bone exactly equal in size and shape to the defect, and having a third of an inch projecting fringe of fibrous pericranium. The flap is swung across and stitched in its new position (Fig. 3). Extra fixation may be secured by undercutting the margin of the freshened area of bone round the defect, and slotting the edge of the graft beneath the overhanging rim (Fig. 4).

\section{Report of a Case}

A youth, aged 22, was referred to me by Dr. Reid of Wrexham. He had been kicked on the head by a horse, and had sustained a compound comminuted depressed fracture of the right frontal bone. The wound had been excised by Dr. Reid, and the depressed fragments of bone removed. An excellent recovery had been made, and there were no intracranial complications. There was, however, a disfiguring puckered scar above the right eyebrow, with a very obvious depression of the forehead above this. The gap in the skull measured two by two and a half inches, and cerebral pulsation was clearly visible. The reconstruction operation was deferred until six months after the injury. A pedicle bone graft was then transplanted from the parietal to the frontal region. Convalescence was uneventful, and now, six months after operation, the youth regards himself as completely cured. There is no cosmetic defect, the graft being firmly fused in its new position and capable of withstanding heavy pressure and percussion without symptoms. There have been no headaches and no other symptoms since operation. The parietal region from which the graft was removed cannot be distinguished from normal bone either clinically or radiologically.

\section{SUMMARY}

A new operation is described for the repair of defects in the vault of the skull by a pedicle bone graft. The advantages of the operation are that the graft may be cut of any size, it has the same curved contour as the skull, it lives through its pedicle, there is excellent fixation of the graft to its bed, and no pressure is exerted on the exposed meninges and cerebrum. A case is reported in which the operation has been successfully performed.

\section{PEDUNCULATED THROMBUS OCCLUDING THE LEFT AURICLE \\ BY}

BARBARA WOODHEAD, M.B., M.R.C.S.

HOUSE-PHYSICIAN, THE QUEEN'S HOSPITAL, BIRMINGHAM

(With Special Plate)

Apart from the vegetations of endocarditis, true intracardiac thrombi are uncommon. Two types are known: loose ball thrombi, and pedunculated thrombi which may become detached and persist as ball thrombi. Ball thrombi do not become organized, are frequently multiple, and rarely give rise to symptoms. Mitral stenosis is usually an associated lesion. Pedunculated thrombi, on the contrary, are generally organized, frequently give rise to symptoms similar to or even indistinguishable from those of mitral stenosis, and are found in a heart which, except for the local effects of the thrombus-thickening of the valves due to trauma and compensatory dilatation of the right ventricle-would otherwise be normal. The left auricle is the more usual situation for intracardiac pedunculated thrombi. The following case of a pedunculated thrombus of the left auricle is of interest both clinically and pathologically.

\section{Clinical History}

A woman, aged 39, a screw-turner, was admitted to the Queen's Hospital, Birmingham, on April 18th, 1932; she was anaemic in appearance, but showed no evidence of cardiac failure. Her symptoms began eighteen months previously, when, owing to frequent attacks of tonsillitis, her tonsils were removed. Since then she had complained of increasing weakness, fatigue, and shortness of breath on the slightest exertion, with the result that she had been compelled to stop work; a frequent symptom was a feeling of extreme faintness on bending down. During the last four months she had been more or less bed-ridden on account of these symptoms, but there was no evidence of cardiac disease until, a week before admission, the development of a presystolic apical murmur suggested a clinical diagnosis of mitral stenosis without cardiac failure. There was no history of rheumatic disease.

\section{Examination}

The patient was a small, pale woman, wasted, and with slight exophthalmos; slight oedema of the ankles was also present. Blood pressure was $110 / 74$; pulse rate $90-100$, regular rhythm, small volume, poor tension. The apex beat 
was in the fifth space, three and a half inches from the midline, and was forceful and heaving. A presystolic thrill was felt all over the praecordium, more marked at the cardiac apex. At the mitral area the first sound was loud and slapping, and was preceded by a crescendo presystolic murmur. At the pulmonary area the second sound was accentuated. Electrocardiogram: sinus rhythm 80; normal auriculo-ventricular conduction times, right ventricular preponderance ; angle 120 degrees ; slurring of QRS in Lead III ; inverted $T$ wave in $I$ and $I I ; P$ wave diphasic.

Respiratory system was normal, except for a few rales and rhonchi at bases and in axillae. The liver and spleen were not palpable, and there was no ascites. Blood picture: 4,140,000 red cells per c.mm.; haemoglobin 48 per cent.; colour index 0.58 ; white blood cells 22,000 per c.mm.; polymorphs 83.25 per cent.

\section{Progress}

On the second day after admission, since the patient was reasonably well and able to be moved without discomfort, she was sent to the $x$-ray department. There she suddenly become dyspnoeic and distressed; she was very pale, with a cold, clammy skin, and air-hunger was marked, the general appearance resembling the picture seen in severe haemorrhage. The pulse was feeble and rapid, the heart sounds extremely faint; no thrill was felt and no murmur was audible. Stimulant treatment provoked no response. Oedema of the lungs developed, and the patient died about fifteen hours after the onset of these severe symptoms. At no time was her pallor replaced by cyanosis:

\section{Post-mortem Findings}

The pericardium contained a slight excess of fluid. The right auricle and right ventricle were dilated, but there was no antemortem thrombus. The left ventricle was normal. The left auricle was filled by a mass the size of a large hen's egg, attached by a firm pedicle to the interauricular septum at an area posterior to the foramen ovale, which was not completely closed. The tumour (Fig. 1), measuring $6 \times 3.5 \times 3.5 \mathrm{~cm}$., was slightly lobulated, yellowish-brown in colour, gelatinous in consistence, and contained areas of haemorrhage. The mitral valve appeared slightly thickened, but there were no old or recent vegetations, and the mitral orifice was of normal size. There was no evidence of any primary valvular disorder. Microscopically the auricular " tumour" showed areas of red and white blood cells, granular debris, and fibrin. In the more completely organized areas were polymorphonuclear and plasma cells, newly formed thin-walled blood vessels, and fibroblasts. In places the scanty, rather stellate fibroblasts in a clear matrix resembled myxomatous tissue (Figs. 2, 3, and 4).

\section{Comments}

There are certain features in this case which belie the presumptive diagnosis of mitral stenosis. One would expect cyanosis and venous congestion in a case of mitral stenosis which was so severe as to cause the patient to be bed-ridden. The pallor can be explained by the intermittent blocking of the mitral orifice; there was no continuous damming of the venous circulation, yet sufficient impediment to cause an anaemia of the tissues. A feeling of faintness on bending down was in all probability due to the alteration of position causing the thrombus to rest on the mitral orifice and to occlude it, so producing a sudden systemic anaemia.

Of particular interest is the comparatively sudden death, which does not usually occur in uncomplicated mitral stenosis. On changing the position of the patient the mobile tumour occluded the mitral orifice; the tumour had by then attained such a size that it could not be dislodged, and the patient died from failure of the blood to pass through the mitral orifice. Although the latter was normal in size, electrocardiographic examination showed a diphasic $\mathrm{P}$ wave, which has been considered characteristic of mitral stenosis due to valvular disease.

A common feature of previously reported cases has been transitory discoloration of the extremities with a state of mild shock. Occasionally gangrene of all the fingers and toes has been noted. These signs have been considered diagnostic of intracardiac thrombi. Although this patient had attacks of faintness or mild shock, there was never any discoloration of the extremities. No cause could be found for the origin of the "tumour" ; there were no dilated veins on the interauricular septum, the auricular contractions were quite regular, the mitral orifice of normal size, and the only abnormality was a slight patency of the foramen ovale.

I am greatly indebted to Dr. Cloake for permission to publish this case, and also for his kind assistance and that of Dr. Neale.

\section{BibliogRAPHY}

Allbutt and Rolleston: System of Medicine, vol. vi, p. 721.

Schwartz and Biloon: Occluding Thrombi of the Left Auricle, Amer. Heart. Journ., 1931, vii, 84.

\section{Memoranda MEDICAL, SURGICAL, OBSTETRICAL}

\section{CERVICAL RIB WITH VASCULAR COMPLICATIONS}

(With Special Plate)

Cervical ribs causing vascular complications are rare. In a recent paper Professors Telford and Stopford ${ }^{1}$ have reported three such cases. The conclusions they draw are that the arterial condition is one of spasm followed by thrombosis, the spasm being induced by the continued irritation of those sympathetic nerves supplying the artery. The sympathetic nerve supply of the artery below the insertion of the pectoralis major is received from the main nerve trunks, and it is these sympathetic fibres which are compressed against the cervical rib and consequently irritated while still an undistributed bundle cn the under surface of the lowest trunk of the plexus. They have shown that the vascular complications depend ertirely upon the distribution of the sympathetic nerve fibres in the lowest trunk. The old view that these complications are due to actual mechanical compression of the subclavian artery would still appear to have certain advocates, and in a recent paper Gladstone and Wakeley ${ }^{2}$ have stated that " the symptoms caused by cervical ribs are those due to pressure upon the subclavian artery and brachial nerve trunks." Professors Telford and Stopford have, I think, proved conclusively that actual mechanical pressure on the artery does not occur in those cases where the vascular symptoms are predominant. In view of the fact that these conclusions do not appear to be generally accepted, I feel that an account of the following case, which entirely corroborates their finding, is justified.

On October 2nd, 1931, a man, aged 24, consulted me and gave the following history. Twelve months previously he first noticed a feeling of general tightness of the left arm and hand whenever he became excited. In February, 1931, while riding a motor cycle, he felt a sudden pain in his left arm and hand, and noticed that the latter had become cold and very blue. At frequent intervals after this date he developed attacks of cramp in all the fingers, associated with a dead white appearance of the skin. The cramp would pass off after a short time, and as the fingers regained their normal colour he would feel a tingling sensation.

On examination the left hand was cold and blue; there was no definite wasting of the thenar or hypothenar muscles. There was slight anaesthesia, chiefly to pin-prick, over the dorsum of the terminal phalanx of the middle finger, but otherwise no involvement of the sensory nerves was manifest.

${ }^{1}$ Telford, E. D., and Stopford, J. S. B.: Brit. Journ. Surg., 1931,

xviii, No. 72.
Gladstone, R. J., and Wakeley, P. G.: Journ. Anat., April, 1932, p. 334. 
BARBARA WOODHEAD: PEDUNCULATED THROMBUS OCCLUDING THE LEFT AURICLE

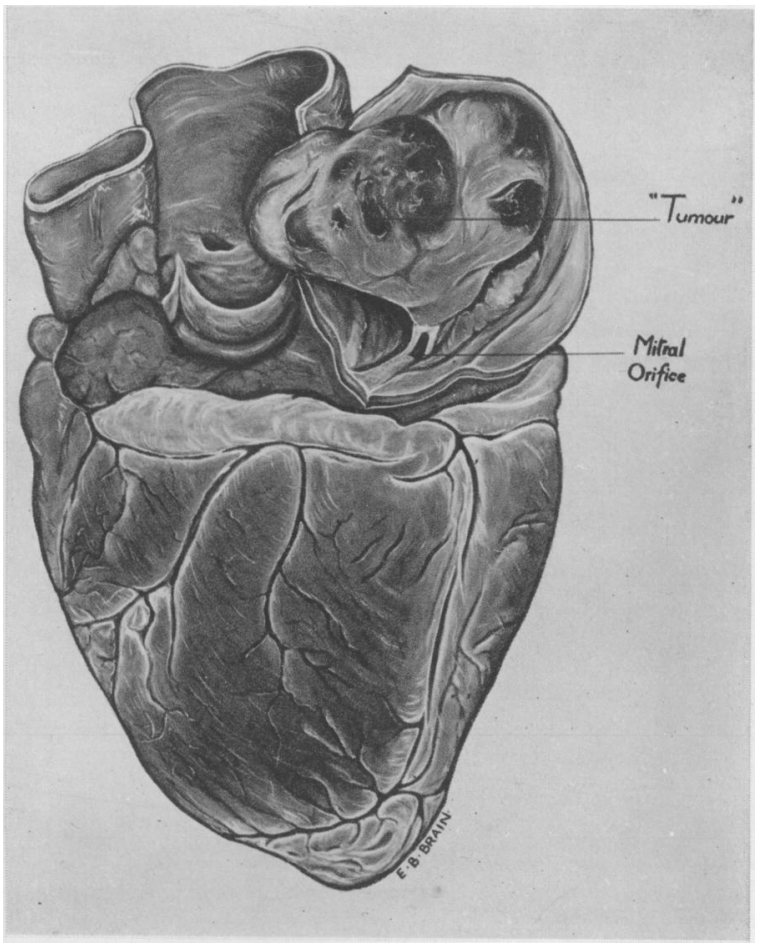

Fio. 1.-A large pedunculated thrombus flling the left auricle

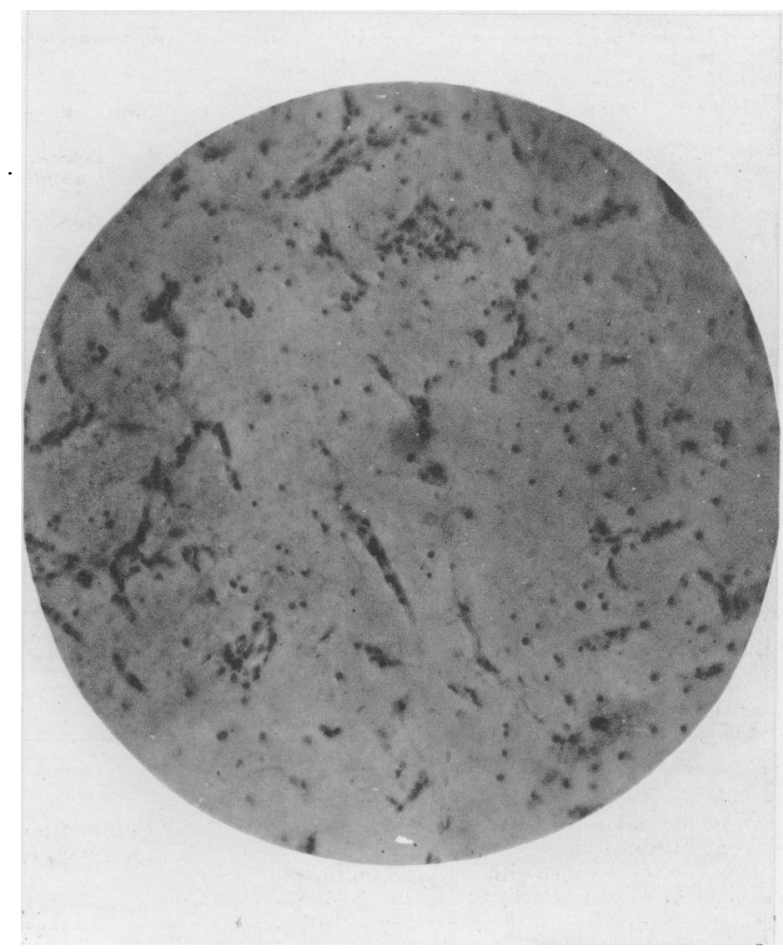

FiG. 2.-Fibroblasts resembling stellate cells of a myxoma.

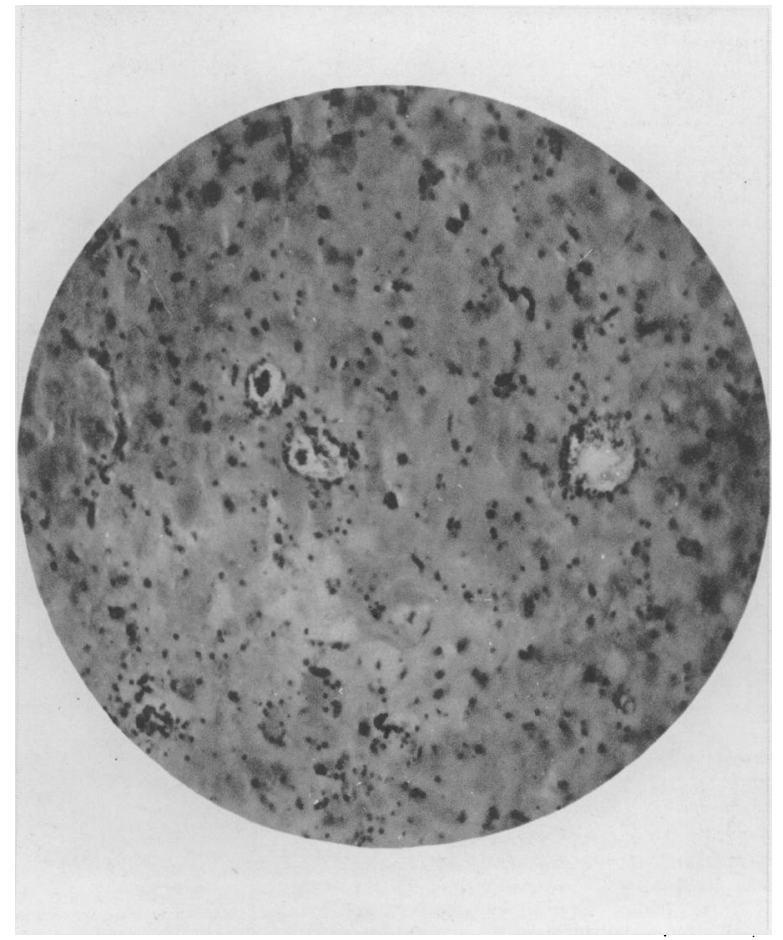

Fig. 3.-Low power. Thin-walled newly formed blood vessels.

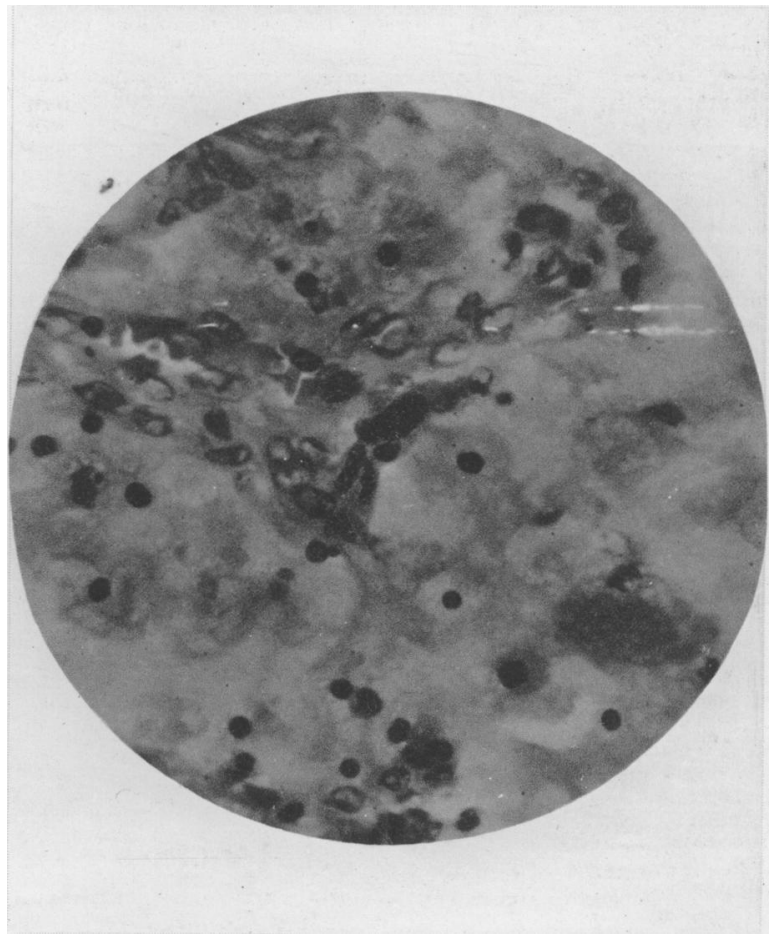

Fig. 4.-High power. Thin-walled blood vessels. 